\title{
Case Report of Acromegalo-Gigantism in Mixed Adenoma
}

\author{
R. Louzolo-Kimbembe , F. El Gharroudi, S. Rafi, G. El Mghari, N. El Ansari
}

Department of Endocrinology, Diabetology, Metabolic Diseases and Nutrition, Mohammed VI University Hospital of Marrakesh, Morocco

DOI: $10.36347 /$ sjmcr.2021.v09i02.007

| Received: 01.02.2021| Accepted: 08.02.2021| Published: 12.02.2021

*Corresponding author: R. Louzolo-Kimbembe

Abstract

Case Report

Before the end of the 19th century, many reports dealing with acromegaly and gigantism appeared. The two syndromes were clinically linked to each other by Brissaud and Miege in 1895; Hutchinson described the pathological similarity in 1900. Thirty-two years later, Cushing reaffirmed that pituitary adenomas were routinely found in patients exhibiting acromegaly or gigantism. He expressed the theory that the relative rarity of gigantism resulted from the recognized lack of adenoma formation in early life. Following Cushing's writings in 1927, scattered case reports dealing with the subject of pituitary gigantism appeared. Recent reports have presented the first detailed studies on human growth hormone (HGH) levels and their response to various manipulations in two giants, but it is still true that much of what is written in textbooks regarding Pituitary gigantism is derived by inference from what is known about the more common acromegaly syndrome in adults.

Keywords: Acromegalo-Gigantism, Pituitary adenoma, human growth hormone (HGH), acromegaly syndrome. Copyright $(\mathcal{C} 2021$ The Author(s): This is an open-access article distributed under the terms of the Creative Commons Attribution 4.0 International License (CC BY-NC 4.0) which permits unrestricted use, distribution, and reproduction in any medium for non-commercial use provided the original author and source are credited.

\section{INTRODUCTION}

Acromegalo-gigantism is a rare condition characterized by extreme size and physical stature occurring in children or adolescents before the epiphyseal growth plaques close (gigantism), followed by acromegaloiddysmorphic syndrome, defining acromegalo-gigantism, due to hypersecretion of growth hormone $(\mathrm{GH})$ most often secondary to a pituitary adenoma which may be pure somatotropic $(60 \%$ of cases) or sometimes mixed [7]. The main symptom of the disease is accelerated abnormal growth affecting the musculoskeletal system associated with other comorbidities. Resection, most often transsphenoidally, is the fastest way to reduce GH and IGF-1 levels. However, complete remission of the disease is usually not achieved with surgery alone, and pharmacological treatment becomes necessary, of which somatostatin analogues are the most common. If no response is obtained with somatostatin analogues, a dopamine agonist or a $\mathrm{GH}$ receptor antagonist may be added. In cases that do not respond to surgery and pharmacological treatment, radiotherapy is used; however, the risk of hypopituitarism should be taken into account [5]. We report the case of a patient followed for acromegalo-gigantism on mixed adenoma, who has had a surgical resection and then placed on a somatostatin analogue and a dopaminergic agonist.

\section{Case Report}

24-year-old patient, who has presented gigantism for 10 years (rapid height gain, change in size) with progressive pituitary tumor syndrome (headache, decreased visual acuity).Follow-up for depressive syndrome on anti-depressant and for diabetes mellitus for 6 months for which he consulted.The requested IGF1 returned to $677.5 \mathrm{ng} / \mathrm{l}$ (normal: 120-238) or 2.8 times normal with a cerebral MRI showing a sellar and suprasellar tissue lesion process measuring $4 * 3.5 * 3.1 \mathrm{cmexerting}$ a mass effect on neighboring structures.Clinical examination revealed a large height (2.02m), acromegaloiddysmorphic syndrome with macroglossia, prominence and enlargement of the nose, bulging fingers and toes, nodular goiter and bilateral gynecomastia. 


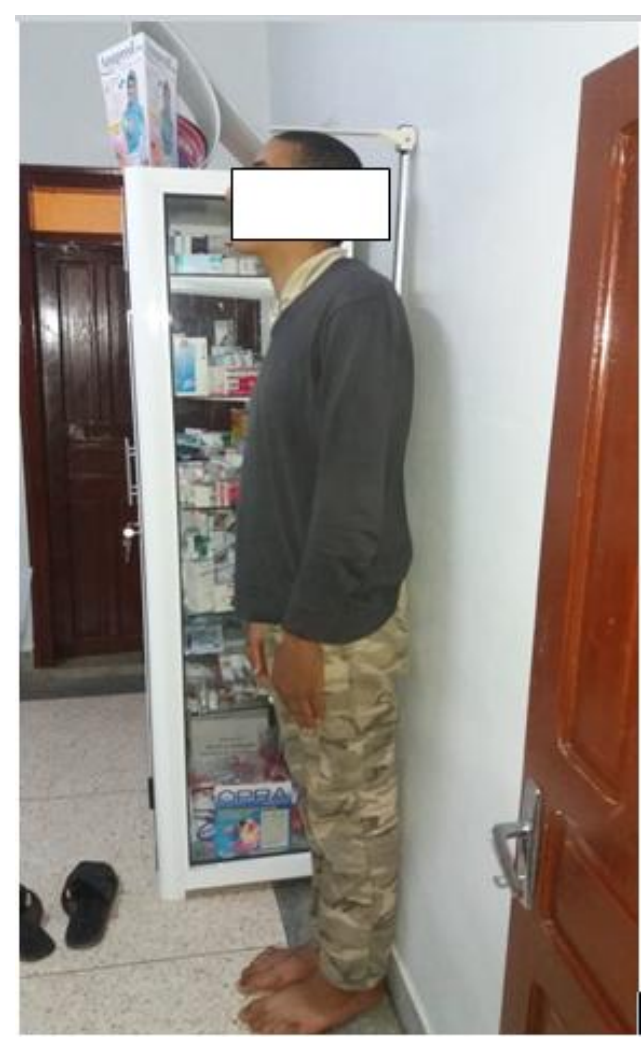

Fig-1: Patient gigantism

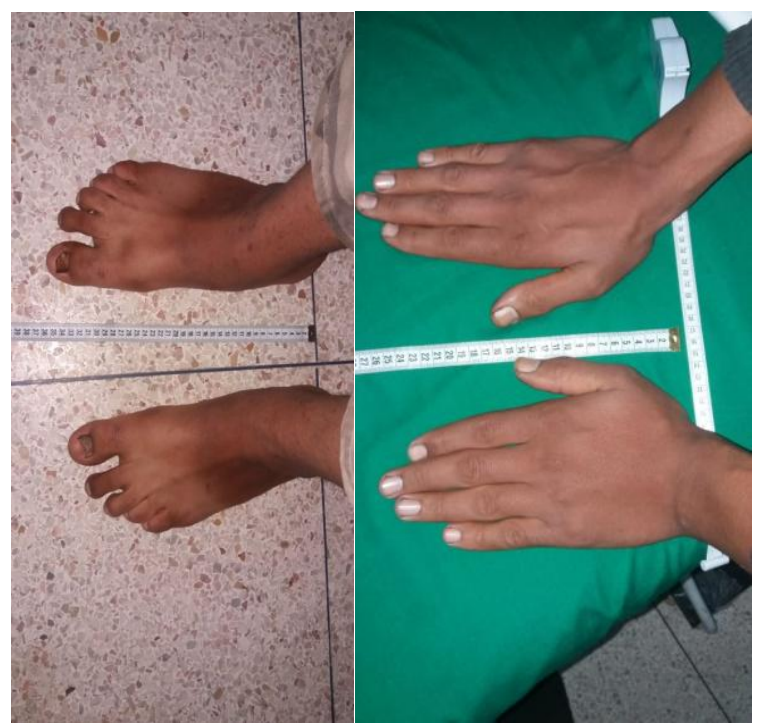

Fig-2: Bulging fingers and toes

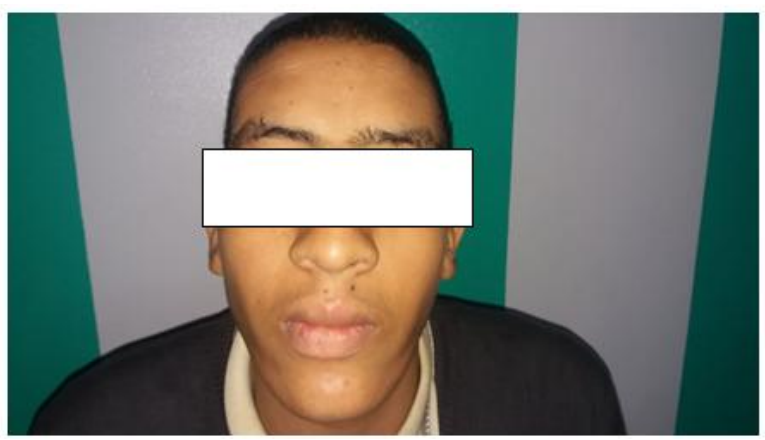

Fig-3: Acrofacial dysmorphia

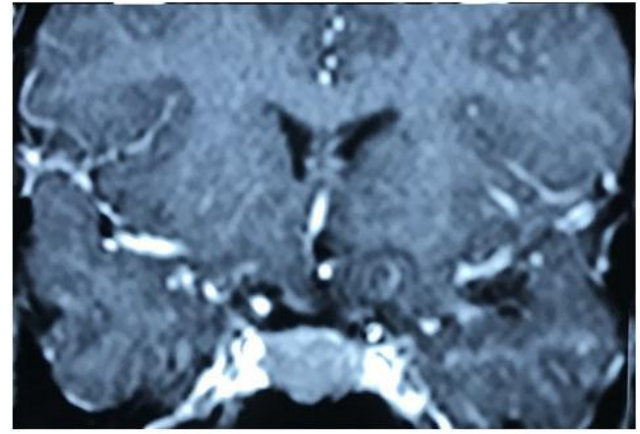

Fig-4: Macroadenoma on MRI

A further work-up revealed a thyrotropic insufficiency, a slight increase in prolactinemia, the electrocardiogram and the Goldman visual field were normal, the cervical ultrasound objectified a multinodular goiter whose fine needle aspiration of the thyroid nodules was benign, the abdominal ultrasound objectified a homogeneous hepatomegaly. The pituitary MRI revealed a sellar and supra sellarlesional process of $2.8 * 4.5 * 3.2 \mathrm{~cm}$ responsible for an enlargement of the sellaturcica with collapse of the sellar floor at the bottom, at the top a filling of the optochiasmatic cistern including the optic chiasma. The diagnosis of acromegalo-gigantism in a mixed pituitary macroadenoma was suggested in view of gigantism and acromegaloiddysmorphic syndrome, confirmed by IGF1 and bilateral gynecomastia. A transsphenoidal surgery was performed with anatomopathology and immunohistochemistry a morphological appearance compatible with a pituitary adenoma expressing the anti $\mathrm{GH}$ antibody and focal $(5 \%)$ the anti prolactin antibody with $4 \%$ Ki67. Postoperative pituitary MRI revealed a tumor residue, the patient was put on somatostatin analogue and dopaminergic agonist (cabergoline), a surgical revision is planned.

\section{DISCUSSION}

Acromegalo-gigantism is an extremely rare disease caused by increased secretion of growth hormone. Gigantism differs from acromegaly in the time of its onset, that is, before and after epiphyseal fusion respectively. The extra large size is very rare these days due to early care. The most consistent biochemical abnormality seen in patients with acromegalo-gigantism is elevated IGF-1. Some patients with hypogonadism responsible for delayed fusion of the epiphyses may continue to grow up to their twenties or even their thirties. The Gold Standard for diagnosing excess $\mathrm{GH}$ is based on the inability to suppress serum $\mathrm{GH}$ to an appropriate level (typically $<1 \mathrm{ng} / \mathrm{ml}$ ) after an oral glucose tolerance test (OGTT). Hyperprolactinemia is also frequently observed, usually due to co-secretion . In fact, adenomas secreting $\mathrm{GH}$ and prolactin are the most frequent mixed adenomas, either they contain both cell types, or they are developed from a stem cell, mammosomatotropic: the same cells, monomorphic, more mature, express both $\mathrm{GH}$ and prolactin [8]. 
Most GH pituitary adenomas are macro adenomas (approximately $80 \%$ of cases) and 30 to $60 \%$ are invasive. A higher frequency in men is reported in the literature. A late diagnosis of acromegalo-gigantism can occur due to poor understanding of the extent of symptoms, delayed consultations, and limited knowledge of the disease by general practitioners. It is the case with our patient who consulted several times for co morbidities linked to his acromegalo-gigantism before being referred to us. The therapeutic goals are to relieve symptoms, reduce tumor volume, prevent recurrence and improve long-term morbidity and mortality. The criteria for cure or good control are now much more stringent: it is required that the concentration of $\mathrm{GH}$, be reduced to less than $1 \mu \mathrm{g} / 1$ or $3 \mathrm{mIU} / 1$ and IGF- 1 is standardized. To achieve these goals, a multi-step treatment strategy is often required. In acromegalo-gigantism, surgery is the procedure of first choice and can be curative. When surgical treatment is indicated as a first-line treatment, it makes it possible to obtain an immediate result if the resection is complete. The most commonly used way in pituitary adenoma surgery is the transsphenoidal one. This technique is minimally invasive and causes limited side effects and postoperative complications .

Several factors influence the effectiveness of surgical treatment:

- Supra-sellar extension, degree of intracavernous invasion and patient age.

- The size of the tumor: the larger the size of the adenoma, the less effective the surgical treatment, on the other hand, well limited non invasive adenomas have a very good prognosis.

- Preoperative GH and IGF1 levels: the lower they are, the better the postoperative remission. Finally, the other essential factor to take into account is the experience of the neurosurgeon.

Because pituitary surgery is a very specialized surgery, remission rates are better in teams that are used to frequently operating pituitary adenomas. Biochemical control is obtained in approximately $70 \%$ of patients with intrasellarmicroadenomas, although this rate is lower with macroadenomas (approximately $40 \%$ ). In view of this poor biochemical control by surgery, patients with acromegalo-gigantism generally require additional pharmacological management with somatostatin analogues. Dopaminergic agonists are useful in cases of associated hyperprolactinaemia or as adjunct therapy to somatostatin analogues in cases with lack of biochemical control and IGF-1 levels up to 1.5 times greater than normal range. Because according to a meta-analysis, cabergoline normalizes IGF-1 in 34\% of patients, rather those whose IGF-1 is moderately increased $[5,8]$.

If there is no response to somatostatin analogues, combination with a GH receptor antagonist is recommended.Appropriate monitoring with testing should be done due to the risk of tumor growth even with adequate biochemical response and improvement in symptoms. The use of radiotherapy as a third-line treatment should be considered, but the risk of hypopituitarism should be considered.To avoid the continued growth of flat bones in patients with tumor residue, management with somatostatin analogues is required, although the best option for residual tumors is combination therapy between somatostatin analogues andGH receptor antagonists [5].

\section{CONCLUSION}

This article highlights the difficulty of managing acromegalogigantism, in particular the unsatisfactory results of transsphenoidal surgery. It is important to note that the diagnosis is often late and transsphenoidal surgery is the first treatment, and due to the poor biochemical control, pharmacological treatment with somatostatin analogues is necessary. The association with dopaminergic agonist is systematic especially in the case of associated perprolactinemia. In case of residual tumor and lack of control by somatostatin analogues, combination with GH antagonists is recommended.Raiotherapy remains the last intention.

\section{REFERENCES}

1. Beckers A, Rostomyan L, Potorac I, Beckers P, Daly AF. X-LAG: How did they grow so tall?.InAnnalesd'endocrinologie. 2017 Jun 1 (Vol. 78, No. 2, pp. 131-136). Elsevier Masson.

2. Verloes A, Stevenaert A, Teh BT, Petrossians P, Beckers A. Familial acromegaly: case report and review of the literature. Pituitary. 1999 May;1(3):273-7.

3. Bhattacharjee R, Roy A, Goswami S, Selvan C, Chakraborty PP, Ghosh S, Biswas D, Dasgupta R, Mukhopadhyay S, Chowdhury S. Pituitary gigantism: A case report. Indian journal of endocrinology and metabolism. 2012 Dec;16(Suppl 2):S285.

4. Haigler ED, Hershman JM, Meador CK. Pituitary gigantism: A case report and review. Archives of internal medicine. 1973 Oct 1;132(4):588-94.

5. García WR, Cortes HT, Romero AF. Pituitary gigantism: a case series from Hospital de San José (Bogotá, Colombia). Archives of endocrinology and metabolism. 2019 Aug;63(4):385-93.

6. Khalil I, El Aziz S, Chadli A. Acromégalogigantisme: à propos d'un cas. InAnnalesd'Endocrinologie 2018 Sep 1 (Vol. 79, No. 4, p. 344). Elsevier Masson.

7. Chapman M. Gigantisme et acromégalie, Manuel MSD, 2019.

8. Chanson P, Young J. Acromégalie, Traité d'Endocrinologie 2e edition 2019, chap117, pp 845851 . 